\title{
Fibrinogen Measurement
}

National Cancer Institute

\section{Source}

National Cancer Institute. Fibrinogen Measurement. NCI Thesaurus. Code C64606.

A quantitative measurement of the amount of fibrinogen present in a sample. 